\title{
Unmet health, welfare and educational needs of disabled children in an impoverished South African peri-urban township
}

\author{
G. Saloojee*, M. Phohole*, H. Saloojee† \& C. IJsselmuiden $\ddagger$ \\ ${ }^{*}$ Childhood Disability Research Project, School of Health Systems and Public Health, University of Pretoria, Pretoria \\ †Division of Community Paediatrics, University of the Witwatersrand, Johannesburg, South Africa, and \\ ¥Council on Health Research for Development (COHRED), Geneva, Switzerland
}

\section{Abstract}

Background: Childhood disability in South Africa has failed to receive adequate attention from governmental agencies, such as the health, education and social welfare departments, despite there being more than 1 million disabled children in the country. This study sought to assess the unmet rehabilitation, education and welfare needs of disabled children living in a peri-urban township.

Methods: As no register of disabled children existed, snowball sampling was used to recruit a convenience sample of 156 disabled children living in Orange Farm township near Soweto, South Africa. Children's impairments, their health and educational needs, and the availability and utilization of services were assessed using a structured interview.

Results: Few disabled children attended pre-school (35\%) or school (44\%). Only a quarter (26\%) of children in need of rehabilitation received such services. Children with motor impairments were more likely to receive rehabilitation than those with intellectual impairment (44\% vs. 8\%, $P<0.0001)$. Of the 233 assistive devices required, only $64(28 \%)$ had been issued. Less than half $(45 \%)$ of the children entitled to a social assistance grant were receiving it. Lack of money, limited awareness about available services, and bureaucratic obstacles were the main reasons offered by caregivers for the low utilization of available services and resources.

Conclusion; Children with disabilities living in Orange Farm are not enjoying the rights and services to which they are entitled. Innovative, co-ordinated service delivery strategies, and better-informed caregivers combined with community recognition of, and support for, the needs of disabled children are required to address these unmet needs.

\section{Introduction}

In South Africa, the prevalence of disability is estimated to be between $5.2 \%$ and $6.4 \%$ in children under the age of 9 years (Anderson 1991; Corneljie 1991; CASE 1999; Christianson et al. 2002; Couper 2002). This estimate includes children with motor, sensory and intellectual disabilities, and is based on four studies, three of which were rural-based. Considering that there were 17 million children aged under 18 years in South Africa in 2001 (Statistics SA 2003), this extrapolates to about 1 million disabled children living in the country.

The Convention on the Rights of the Child and the South African constitution guarantees children with disabilities the right to basic health care and education. Free health care is available for all children under the age of 6 years in South Africa. Adults and children with a disability are also eligible for free health care 
since 2004. A care dependency grant of R740 (about US\$110) is available for disabled children between 1 and 18 years of age requiring full-time support and care. The education department has a 20-year plan that promotes full integration and participation into mainstream schools of all learners who experience barriers to learning.

However, despite increasing public awareness of disability issues and rights, and a strong political commitment on the part of the new South African government to address inequities and discrimination encountered by children with disabilities, a large hiatus still exists between policies and their implementation.

Ten years into the new democratic South Africa, many of the needs of disabled children remain unmet and continue to be ignored. To investigate and quantify the extent of these unmet needs, a study was undertaken in a disadvantaged peri-urban South African township to establish whether children with disabilities had access to education, rehabilitation (including the provision of assistive devices) and social grants, and to describe support systems available to caregivers of these children.

\section{Methods}

Orange Farm is situated $30 \mathrm{~km}$ south of Soweto, near Johannesburg. From its humble beginnings as an informal settlement in the early 1980s (during the apartheid era), it has expanded into a sprawling peri-urban township with an estimated population of 300000 people. Residents have access to tap water and electricity but limited sanitation. There are no formal trading areas or banks in the township, the nearest trading centre being $30 \mathrm{~km}$ away. Most people live in one- or two-roomed corrugated iron structures, although some residents have brick dwellings. There is a good, but expensive, transport system (rail and minibus taxis) to the major centres. Few residents own cars. Unemployment affects one-third to one-half of the adult population.

Orange Farm is served by six primary healthcare clinics and 39 schools. The two nearest hospitals are each approximately $30 \mathrm{~km}$ away. There are neither special needs education schools nor community-based rehabilitation services for children with disabilities. Children need to travel to the nearest hospital (Chris Hani Baragwanath Hospital in Soweto) to receive rehabilitation therapy and assistive devices. A single community-based social worker serves the welfare needs of about 120000 children in the settlement. Two care centres (one residential, the other day care only) serving disabled children in Orange Farm accommodate 60 children between them. Both are managed by parents belonging to community-based organizations.

\section{Study population}

A descriptive study design was used. The study population consisted of all disabled children under 18 years of age, resident in Orange Farm. A disabled child was defined as a child with a health or medical condition resulting in difficulty in performing one or more functional activities ('activity limitations') as described by the International Classification of Functioning, Disability and Health developed by the World Health Organization (WHO 2001). As no register of disabled children existed in Orange Farm, a snowball sampling strategy was used to identify children with disabilities. This sampling method, a form of chain-referral sampling, is an accepted way of identifying hidden populations in situations where the absence of register- or map-based sampling frames makes probability sampling difficult (Goodman 1961; Heckarthon 1997). Snowball sampling locates new participants through introductions from initial contact persons. In this study, the initial contact persons were caregivers of disabled children attending the daycare centre in Orange Farm as well 
as caregivers of children who had received rehabilitation therapy at Chris Hani Baragwanath Hospital in Soweto.

\section{Data collection}

The key informant, the child's primary caregiver, was visited at home. Screening questions and clinical observation were used to confirm the child's disability. If positive, the child's primary caregiver was interviewed using a semi-structured questionnaire. The interviews were conducted by one of two paediatric therapists [one a physiotherapist (G.S.); and the other a speech therapist (M.P.)] with extensive clinical experience and skills in working with disabled children in a variety of settings. Each researcher was accompanied by a field worker who was a mother of a disabled child and resident in the study area. The categories of impairments and the criteria for each were those described by Thorburn and colleagues (1992a), namely, hearing, speech, visual, motor and/or cognitive impairment.

Data collection took place during a 4-month period in 2002. Interviews were conducted in the respondent's home language (mainly Sotho and Zulu) and translated into English by the field worker. The interview sought information on school attendance, and whether the child was receiving rehabilitation, social assistance in the form of a care dependency grant (if applicable) and an assistive device (if applicable). Further, caregivers were asked open-ended questions about available support systems or services and their use of these. A pilot study to test the questionnaire was conducted on 10 children with disabilities at the outpatient section of the physiotherapy and speech therapy departments at Chris Hani Baragwanath and Kalafong hospitals.

\section{Data analysis}

EPI-INFO 6.04 (CDC, Atlanta, GA, USA) was used for quantitative data entry and statistical analysis. Qualitative data were analysed according to themes in a descriptive and summative manner only.

Ethical approval was obtained from the Ethics Committee of the Faculty of Health Sciences at the University of Pretoria (Ethical Protocol number 142/2001). Permission to conduct the study in Orange Farm was also obtained from the regional health manager and the local ward councillor. The study was supported by a grant from the W.K. Kellogg Foundation. This study is part of a larger initiative investigating the interactions between childhood disability and health.

\section{Results}

The caregivers of 156 children with disabilities [89 males (57\%) and 67 females (43\%)] were interviewed. The children's age and sex distribution is shown in Fig. 1. Cognitive impairment (39\%) was the commonest disability encountered, followed by motor (27\%), speech (21\%), hearing (7\%) and visual (6\%) impairments. The primary diagnoses recorded during the field visits are shown in Table 1. Cerebral palsy was the commonest primary diagnosis. A total of $102(65 \%)$ of the disabled children were mobile, and able to walk independently $(n=82)$ or with help $(n=20)$. A third $(53 / 156)$ of the children were unable to communicate verbally. 


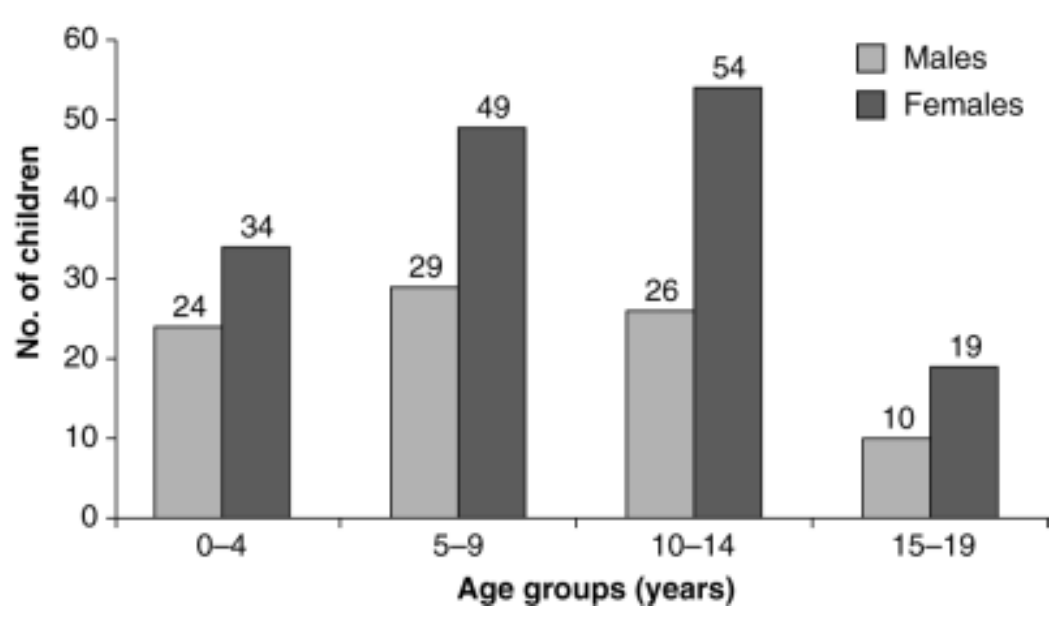

Figure 1. Age and sex distribution $(n=156)$.

Table 1. Primary diagnoses in disabled children

\begin{tabular}{|l|l|}
\hline \multicolumn{1}{|c|}{ Primary diagnosis } & \multicolumn{1}{c|}{$n(\%)$} \\
\hline Cerebral palsy & $67(42.9)$ \\
\hline Moderate cognitive impairment & $26(16.7)$ \\
\hline Severe to profound cognitive impairment & $25(16.0)$ \\
\hline Down syndrome (Trisomy 21) & $10(6.4)$ \\
\hline Hearing impairment & $8(5.1)$ \\
\hline Albinism & $6(3.8)$ \\
\hline Spinal cord lesion & $3(1.9)$ \\
\hline Visual impairment & $3(1.9)$ \\
\hline Developmental delay related to HIV & $2(1.3)$ \\
\hline Speech difficulty & $2(1.3)$ \\
\hline Other syndromes & $2(1.3)$ \\
\hline Other (amputee and developmental delay) & $2(1.3)$ \\
\hline Total & $156(100.0)$ \\
\hline
\end{tabular}

\section{Education}

Only $33(35 \%)$ of children aged 3 years and over had attended or were currently attending pre-school. Of the 92 children of compulsory school-going age (i.e. between the ages of 7 and 15 years), 40 (44\%) were attending a school or specialized institution. Of these 40 children, 22 (55\%) were attending mainstream schools; and $18(45 \%)$ attended a special school, training centre or daycare centre. Thirty (42\%) children of school-going age with motor impairments, and 28 (44\%) children with intellectual impairments were not attending school. 


\section{Rehabilitation}

Of the 143 (92\%) children who could have substantially benefited from rehabilitation therapy, as judged by the researchers, only a quarter [37 (26\%)] were receiving either physiotherapy, occupational therapy and/or speech therapy. Children with motor impairments were more likely to have received therapy than those with intellectual impairments (44\% vs. 8\%, $P<0.0001)$. Ninety-seven $(62 \%)$ children needed one or more assistive devices. Of the 233 assistive devices assessed as being required, 64 (28\%) either had been issued or were being waited for by caregivers. Wheelchairs and pushchairs $(n=55)$ were most needed, followed by communication aids $(n=43)$, specialized seating $(n=33)$ and standing frames $(n=27)$.

\section{Social assistance grants}

More than three-quarters [123 (78\%)] of the children qualified for state-funded care dependency grants according to the criteria specified by the Social Assistance Act 59 of 1992 (Statutes of the Republic of South Africa 1992). This grant is the only form of state-funded assistance available for children with disabilities. Of these, only 55 (45\%) were receiving them. The proportion of children receiving grants did not differ significantly considering the type of disability.

\section{Caregivers' explanations for non-utilization of services}

In open-ended questions, caregivers were asked to provide reasons for the non-utilization of available services. The commonest explanations offered by caregivers are presented in Tables 2 and 3 . Lack of money, poor awareness and knowledge about the right to health care and available services, and bureaucratic obstacles stood out as the major reasons for low utilization of services.

Table 2. Explanations provided by caregivers

\begin{tabular}{|l|l|}
\hline \multicolumn{1}{|c|}{ Three main reasons given by caregivers } & $\%$ \\
\hline For non-attendance at school & 53 \\
\hline School unsuitable for a child with a disability (child 'would not cope') & 27 \\
\hline Family financial difficulties & 13 \\
\hline School refused to accept child & 36 \\
\hline For not attending rehabilitation & 25 \\
\hline Financial and transport difficulties & 15 \\
\hline No improvement seen in child despite therapy & 29 \\
\hline Unaware that child could benefit from therapy & 28 \\
\hline For not receiving social grants & 20 \\
\hline Unaware that child qualified for a grant & \\
\hline $\begin{array}{l}\text { Caregiver did not have the necessary documentation (such as child's birth certificate, or caregiver's identity } \\
\text { document) }\end{array}$ & 2 \\
\hline Administrative and bureaucratic obstacles & \\
\hline
\end{tabular}


Table 3. Some reasons offered by caregivers for the low utilization of services

\begin{tabular}{|l|}
\hline Regarding education \\
\hline I stopped taking him to school because the other children were walking all over him \\
\hline The school refused to take her because she was disabled (I tried two schools) \\
\hline This child will never have coped at school \\
\hline This child can't do anything - she is just a 'thing' \\
\hline Regarding rehabilitation \\
\hline I saw no improvement in my child - he can still not walk or talk even though he was attending (rehabilitation) \\
since a baby \\
\hline I used to take him but now I have another baby and I cannot manage financially \\
\hline I have arthritis and now I cannot carry my child for long distances \\
\hline This child is too disabled - there cannot be any more help \\
\hline Regarding social assistance grants \\
\hline I have lost hope - I have been waiting for so long \\
\hline I applied and they said I had the wrong forms. I am still waiting for the forms \\
\hline The child was born like this and we are used to making ends meet somehow \\
\hline I have heard about this grant but I don't know where to go \\
\hline \hline
\end{tabular}

\section{Support services}

Apart from the two care centres run by parents, no other local organizations caring for disabled children in Orange Farm existed. None of the caregivers interviewed belonged to a parents' support group or a disabled people's organization. Emotional support was mainly provided by the caregiver's immediate family.

\section{Discussion}

It is well recognized that a formidable gap exists between the needs of, and the services available to, children with disabilities in resource-constrained settings (Thorburn et al. 1992b; Pongprapai et al. 1996; Couper 2002). More than one-half of the children in our study were denied access to schooling, and less than one-half of eligible children were recipients of social assistance grants. Similarly, it was disturbing that only a quarter of children in need of rehabilitation therapy were actually receiving it.

This study mirrors previous data on the epidemiology of disability in children in South Africa as well as the many problems recognized as complicating their optimal participation in daily activities. Two-thirds of all disabled children had either a cognitive or a motor disability or both, and cerebral palsy was the biggest contributor to the burden of childhood disability. 
Our findings are not dissimilar to studies in other under-resourced settings globally. A Jamaican study of 193 disabled children identified their most frequent needs as being special education (62\%) and communitybased rehabilitation (nearly 30\%) (Thorburn et al. 1992b). Only 5\% of children with cognitive disabilities and $33 \%$ of children with gross motor disabilities had accessed the relevant services. Seizures were the only condition for which a reasonable degree of care was available, to about $68 \%$ of participants. In a poor rural community in Thailand (Pongprapai et al. 1996), 66\% of children identified as disabled during a populationbased disability survey of 1836 households were assessed as being likely to achieve benefit from rehabilitation or surgical services (i.e. corrective surgery, rehabilitation and assistive devices). Just more than one-half $(55 \%)$ of school-aged disabled children attended school, and only $35 \%$ had sought allopathic (Western) medical treatment. In a rural part of South Africa, only a third of children requiring rehabilitation were known to the rehabilitation services (Couper 2002).

The unavailability and inaccessibility of services combined with financial constraints and ignorance of available services were reasons put forward in Thailand and Jamaica for these unmet needs (Thorburn et al. 1992b; Pongprapai et al. 1996). These explanations resonate with our study findings. Further, we identified inadequate and inaccessible transport, lack of visible progress in the child's abilities following therapy, as well as poor administration of services as other explanations offered for the low utilization of available services.

The sense of despair and hopelessness felt by caregivers of more severely disabled children was unmistakable. The experience of caregivers of disabled children is often one of 'being pushed from pillar to post' in a bureaucratic maze of paperwork and indifference, punctuated by a lack of information, misinformation and even disinformation when trying to apply for a social assistance grant (Zungu et al. 2003), or ignorance of policies and a lack of empathy from teachers and principals when trying to place the child at a school.

Living in an impoverished environment where unemployment rates are high, where many children live in single-parent families with little or no support from fathers, and where household incomes are very low, adversely affects a caregiver's ability to prioritize the care that a child with a disability needed. Consequently, regular visits to a hospital $30 \mathrm{~km}$ away for rehabilitation therapy, when the transport costs for one return trip alone may consume as much as $5 \%$ of the average family's monthly income, is difficult for caregivers to justify, unless spectacular results are evident. Such dramatic improvements are, of course, difficult to attain in any situation of chronic disability, let alone with the once-monthly therapy sessions usually offered by an overburdened public hospital outpatient therapy department.

Compounding this problem is the reality that most people caring for disabled children in Orange Farm are dependent on an informal public transport that does not accommodate children with disabilities. This compels caregivers to either use an expensive private transport or carry their disabled children to services by themselves. Thus, even if services were more easily available, making the services accessible requires different considerations and planning than in the case of non-disabled children.

As Orange Farm is similar to many other informal settlements, the findings of this study are probably generalizable to most other disadvantaged areas in South Africa. As our screening methods excluded children with mild or 'invisible' impairments, such as mental illnesses or mild intellectual impairments (learning disabilities), the extent of the unmet needs described in this study is likely to be a conservative estimate. The study also excluded children with chronic medical, emotional or behavioural problems (such as asthma or autism). In the United States, for example, $18 \%$ of children were classified as having a chronic condition requiring additional health and related services (Newacheck et al. 1998), which serves to reiterate our view that this study underestimates real needs. 
There were a few important limitations in this study. The non-existence of a register or central database of children with disabilities meant that children were mainly identified with the help of community members. This hindered the selection of a random sample as well as the identification of disabled children 'hidden' from the community. Another limitation was that the researchers assessed the condition of children and their needs on a limited examination in the home. However, both primary researchers were highly skilled and experienced at this task. Finally, we chose not to collect data on children with mild impairments or chronic health conditions who also need access to health, rehabilitation and educational services.

How do healthcare professionals best respond to difficult situations such as those identified in this study? There is a danger of resigning oneself to continuing to do what one does best (i.e. remaining in the traditional role of therapist or doctor) while waiting for others to resolve the broader problems. However, in situations like this, it is not only appropriate, but essential, for healthcare providers to recognize the situation they are working in (as outlined in the article), and review the services they are providing. This could include participating in any outreach services and projects, creating and facilitating support networks for caregivers, offering parents accurate information on available resources and access to these, as well as initiating community-based rehabilitation services.

More importantly, a co-ordinated response to the problems identified is required. We found little evidence of co-operation between the health, education and social development departments regarding disability. Consequently, these services were fragmented and parents ill-informed of the available resources. Our view is that disability in the context of poverty, and any strategies that target disadvantaged children, are best addressed at a district level. In addition, we believe that many basic needs could be met in the community and do not require highly specialized personnel. Thus, for example, caregivers of disabled children could be trained and employed by district services to facilitate links at a household level between governmental service providers and caregivers of children with disabilities.

Children with disabilities living in Orange Farm are clearly not enjoying the rights and the services to which they are entitled under the South African Constitution and current legislation. Further research is needed to identify and test the efficacy of innovative service delivery strategies, such as the impact that targeted transport subsidies may have on improving healthcare access for disabled children. Ten years after democracy in South Africa, the country is still failing its disabled children. They deserve better.

\section{Acknowledgements}

Grateful thanks are extended to Elizabeth Borephe and Matlalepule Mtlare for their assistance with the field work and to all caregivers who participated in this study. Funding for the study was received from the W.K. Kellogg Foundation.

\section{References}

Anderson, G. M. (1991) Prevalence, nature and severity of disability in Tiyani. [MSc (Med) Thesis]. Faculty of Medicine, University of the Witwatersrand, Johannesburg, South Africa

Christianson, A. L., Zwane, M. E., Manga, P., Rosen, E., Venter, A., Downs, D.\&Kromberg, J. G. (2002) Children with intellectual disability in rural South Africa: prevalence and associated disability. Journal of Intellectual Disability Research, 46, 179-186.

Community Agency for Social Enquiry (CASE) (1999) We Also Count! The Extent of Moderate and Severe Reported Disability and the Nature of the Disability Experience in South Africa. Department of Health, Pretoria, South Africa Available at: http://0-www.doh.gov.za.innopac.up.ac.za:80/facts/1997/case.pdf (accessed on 20 March 2005). 
Corneljie, H. (1991) The prevalence of impairment, disability and handicap and the pattern of motor disability in the Gelukspan health ward. [MSc (Med) Thesis].

Faculty of Medicine, University of the Witwatersrand, Johannesburg, South Africa

Couper, J. (2002) Prevalence of childhood disability in rural KwaZulu Natal. South African Medical Journal, 92, 549552.

Goodman, L. A. (1961) Snowballing sampling. Annals of Mathematical Statistics, 32, 148-170.

Heckarthon, D. (1997) Respondent-driven sampling: a new approach to the study of hidden populations. Social Problems, 44, 174-199.

Newacheck, P. W., Strickland, B., Shonkoff, J. P., Perrin, J. M., McPherson, M., McManus, M., Lauver, C., Fox, H.\&Arango, P. (1998) An epidemiologic profile of children with special health care needs. Pediatrics, 102, 117-123.

Pongprapai, S., Tayakkanonta, K., Chongsuvivatwong, V.\&Underwood, P. (1996) A study on disabled children in a rural community in southern Thailand. Disability and Rehabilitation, 18, 42-46.

Statistics South Africa. (2003) Census 2001. Statistics SA, Pretoria, South Africa.

Available at: http://0-www.statssa.gov.za.innopac.up.ac.za:80/census01/Census/dialog/statfile.asp (accessed on 14 March 2005).

Statutes of the Republic of South Africa. (1992) Social Assistance Act 59 of 1992. Salaries and pensions. Issue 33, 431-447.

Thorburn, M. J., Desai, P.\&Davidson, L. L. (1992a) Categories, classes and criteria in childhood disability - experience from a survey in Jamaica. Disability and Rehabilitation, 14, 122-132.

Thorburn, M. J., Desai, P.\&Paul, T. J. (1992b) Service needs of children with disabilities in Jamaica. International Journal of Rehabilitation Research, 15, 31-38.

World Health Organization. (2001) International Classification of Functioning, Disability and Health. WHO, Geneva, Switzerland

Zungu, S., Moitse, S.\&Hosegood, V. (2003) Beating a path through a maze of bureaucracy. ChildrenFIRST, 7, 5-8. 